\title{
Depressive Symptoms among Pregnant Women Screened in Obstetrics Settings
}

\author{
SHEILA M. MARCUS, M.D., ${ }^{1}$ HEATHER A. FLYNN, Ph.D., ${ }^{1}$ FREDERIC C. BLOW, Ph.D., ${ }^{2}$ \\ and KRISTEN L. BARRY, Ph.D. ${ }^{2}$
}

\begin{abstract}
Objectives: This study aimed to describe the prevalence of depressive symptomatology during pregnancy when seen in obstetric settings, the extent of treatment in this population, and specific risk factors associated with mood symptoms in pregnancy.

Methods: A total of 3472 pregnant women age 18 and older were screened while waiting for their prenatal care visits in 10 obstetrics clinics using a brief (10 minute) screening questionnaire. This screen measured demographics, tobacco and alcohol (TWEAK problem alcohol use screening measure), and depression measures, including the Center for Epidemiological Studies-Depression scale (CES-D), use of antidepressant medications, past history of depression, and current treatment (i.e., medications, psychotherapy, or counseling) for depression.

Results: Of women screened, $20 \%(n=689)$ scored above the cutoff score on the CES-D, and only $13.8 \%$ of those women reported receiving any formal treatment for depression. Past history of depression, poorer overall health, greater alcohol use consequences, smoking, being unmarried, unemployment, and lower educational attainment were significantly associated with symptoms of depression during pregnancy.

Conclusions: These data show that a substantial number of pregnant women screened in obstetrics settings have significant symptoms of depression, and most of them are not being monitored in treatment during this vulnerable time. This information may be used to justify and streamline systematic screening for depression in clinical encounters with pregnant women as a first step in determining which women may require further treatment for their mood symptoms. As elevations in depressive symptomatology have been associated with adverse maternal and infant outcomes, further study of the impact of psychiatric treatment in gravid women is essential.
\end{abstract}

\section{INTRODUCTION}

A LMOST ONE WOMAN IN FOUR will experience depression at some point in her life, ${ }^{1}$ most commonly during the childbearing years. ${ }^{2,3}$ Women who experience depressive symptoms associated with childbearing are at greatly increased risk for future depressions over a 5-year period. ${ }^{4-6}$

\footnotetext{
${ }^{1}$ Department of Psychiatry, Women's Mood Disorders Program, University of Michigan Depression Center, University of Michigan Medical School, Ann Arbor, Michigan.

${ }^{2}$ VA Serious Mental Illness Treatment Research and Evaluation Center, Health Services Research and Development, Department of Veterans Affairs Medical Center, and Department of Psychiatry, University of Michigan, Ann Arbor, Michigan.

All work for this report was conducted at the Department of Psychiatry, University of Michigan Medical School, and was supported by the University of Michigan Health System.
} 
Self-reported maternal mood symptoms during pregnancy have been associated with poor birth outcomes, including low birth weight, increased risk of premature delivery, and preeclampsia in the mother, ${ }^{7,8}$ as well as with impaired health functioning for the mothers. ${ }^{9}$ Antenatal mood symptoms often predate postpartum depression, ${ }^{10}$ and mood difficulties in women with infants are associated with poor outcomes in their children.

Zuckerman et al. ${ }^{11}$ found a significant association between maternal elevated Center for Epidemiological Studies-Depression (CES-D) scores during pregnancy and unconsolability and excessive crying in their infants. Beginning in the first few months of life, maternal depressive symptomatology has been shown to affect responsiveness to the child, ${ }^{12}$ behavioral problems, and delayed cognitive and linguistic development. ${ }^{13-15}$ Many studies exploring postpartum illness do not differentiate between research diagnostic criteria for major depression and minor depression. There has been ample research in nongravid women to suggest that minor depression, not of sufficient duration or severity to meet the criteria for a major depressive episode, has a significant and disabling impact. ${ }^{16-19}$

Although there have been advances in psychopharmacological and psychotherapeutic treatment for depression, many pregnant women do not seek treatment. A recent study of mental health issues in pregnancy found that only 1 in 5 women with a psychiatric disorder in obstetrics settings had evidence of treatment in the medical charts. ${ }^{20}$ Another investigation found that a diagnosis of depression was made in only $0.8 \%$ of childbearing women based on a review of diagnostic codes across a large hospital system. ${ }^{21}$ Studies to date have not directly examined the utility of screening for antenatal depression in obstetrics settings for optimizing rates of identification and appropriate treatment. However, the U.S. Preventive Task Force concluded recently that screening for depression in adults in primary care can improve rates of detection and treatment when adequate follow-up mechanisms are in place in the setting. ${ }^{22}$ At this point, there are no clear guidelines for appropriate treatment of antenatal and postnatal depression. However, Wisner et al. ${ }^{23}$ have presented a risk-benefit decision-making model that incorporates a number of factors, including the risks and benefits of medication use and attitudes and preferences of the patient, her family, and her obstetrician. The antenatal visit may provide an ideal venue for initial screening and intervention, as (1) the perinatal period is a high risk time for the emergence of depressive symptoms and (2) most pregnant women will seek prenatal care at some point during their pregnancy.

Identification of risk factors for elevated depression in pregnancy may help to target screening efforts. Previous studies have found personal and family history of mood disorder, marital conflict, younger age, and limited social support with greater number of children to be risk factors for depression in pregnancy. ${ }^{24,25}$ A recent study also found scores on a substance abuse screening measure to be significantly associated with antenatal depression, as measured by the Edinburgh Postnatal Depression Scale. ${ }^{26}$ Other data have shown a link between depression in pregnancy and substance abuse, including smoking. ${ }^{27,28}$ Depression in pregnancy has been linked to lower educational attainment, unemployment, and marital status, particularly in lower-income women. ${ }^{29} \mathrm{~A}$ prior history of depression is perhaps the strongest predictor of future depression. ${ }^{30}$ The risk of postpartum depression in women who have histories of depression is high, with estimates ranging from $25 \%$ to $50 \%{ }^{24}$

As antenatal depressive symptoms may have a negative impact on both mother and infant and may predispose women to the development of postpartum depression, three research questions were addressed in this study. First, we examined the prevalence of elevated depressive symptomatology in pregnant women as identified by screening in obstetrics settings. Second, we examined rates of reported receipt of formal treatment (i.e., medications, psychotherapy, or counseling) for depression among those who may be considered at risk for depression. Finally, we examined demographic and psychosocial risk factors associated with elevated depressive symptomatology during pregnancy in obstetrics settings.

\section{MATERIALS AND METHODS}

\section{Procedures}

As part of an ongoing intervention project, pregnant women were screened in obstetrics clinics while waiting for their prenatal care visit. A 
total of 3472 pregnant women were screened in 10 obstetrics clinics in southeastern Michigan. All pregnant women were approached by research staff in the waiting area of the clinics and asked to participate, and $90 \%$ of all women approached agreed to complete the screening survey. Women who chose not to participate refused further contact with the research assistant after the initial approach. Therefore, it was not possible to collect information on their characteristics. Confidentiality was maintained by the use of randomly chosen study code numbers, and all procedures were approved by the University of Michigan Medical School Institutional Review Board. Screening measures included demographic information, ratings of overall health, lifetime and recent depression, current distress (CES-D), risk drinking (TWEAK), and use of prescription medications.

\section{Participants}

Demographic characteristics of participants are shown in Table 1. A wide range of ages was sampled (18-46 years, mean 28.6 (SD 6.0). The racial/ethnic distribution of our sample closely reflects that of our screening county. ${ }^{31}$ Women were screened in the clinical settings at an average of 25 weeks of gestation (SD 10.4), with a range of 3-41 weeks. Most women were married, and most reported educational attainment beyond high school.

\section{Measures}

The screening questionnaire consisted of items assessing demographic characteristics (age, marital status, employment status, educational attainment, parity, weeks gestation, racial/ethnic status), health behaviors during pregnancy (such as overall physical health rated on a 5-point scale from poor to excellent), and use of alcohol and tobacco. Women were asked to indicate whether they had taken medication for depression in the past 2 years, whether they were currently taking the medication, and whether they had discontinued the medication as a result of becoming pregnant or during prepregnancy planning. The screening questionnaire also included the TWEAK as an alcohol screener. ${ }^{32}$ The TWEAK has been found to demonstrate good sensitivity and specificity in screening for risk drinking in women and during pregnancy, ${ }^{33}$ using a cutoff score of 2. It is a 5-item measure, from which a total severity score may be derived.
Table 1. Demographic and Health-Related Characteristics of Study Sample $(n=3472)$

\begin{tabular}{|c|c|}
\hline Characteristic & Result \\
\hline Maternal age (years) & $28.6 \pm 6.0^{\mathrm{a}}$ \\
\hline Parity & $0.87 \pm 1.1^{\mathrm{a}}$ \\
\hline Weeks pregnant at screening & $25 \pm 10.4^{\mathrm{a}}$ \\
\hline Cigarettes smoked per day & $0.38 \pm 1.0^{\mathrm{a}}$ \\
\hline \multicolumn{2}{|l|}{ Marital status (\%) } \\
\hline Married & 74 \\
\hline Live-in partner & 10 \\
\hline Never married & 13 \\
\hline Divorced & 1.4 \\
\hline Separated & 1.3 \\
\hline Widowed & 1 \\
\hline \multicolumn{2}{|l|}{ Race/ethnicity (\%) } \\
\hline Caucasian & 73 \\
\hline African American & 13.3 \\
\hline Asian American & 5.7 \\
\hline Hispanic/Latina & 2.4 \\
\hline Native American & 0.7 \\
\hline Other & 2.4 \\
\hline \multicolumn{2}{|l|}{ Education (\%) } \\
\hline$<8$ th grade & 0.6 \\
\hline Grades 9-11 & 8 \\
\hline High school graduate & 22 \\
\hline Some college & 19 \\
\hline College graduate & 28 \\
\hline Beyond college & 23 \\
\hline \multicolumn{2}{|l|}{ Employed $(\%)$} \\
\hline No & 41 \\
\hline Part time & 19 \\
\hline Full time & 40 \\
\hline \multicolumn{2}{|l|}{ Elevated TWEAK score (\%) } \\
\hline No & 89.7 \\
\hline Yes & 10.3 \\
\hline \multicolumn{2}{|c|}{ Elevated depressive symptoms (\%) } \\
\hline No & 79.6 \\
\hline Yes & 20.4 \\
\hline
\end{tabular}

${ }^{\mathrm{a}}$ Mean $\pm \mathrm{SD}$.

Current depressive symptomatology was measured by the CES-D. The CES-D is used widely as a screening instrument to detect depression in nonclinical populations and has been found to have adequate sensitivity in identifying a diagnosis of major depression based on an interview using the Structured Interview for the DSM-III-R in a primary care population of adult men and women. ${ }^{34}$ Items on the CES-D cover the previous 7 days and are rated on a 4-point scale. A total score is derived by summing the ratings across the 20 items. Good internal consistency (Cronbach's alpha $=0.84$ ) has been found for the CES$\mathrm{D}$ in the general population ${ }^{35}$ and with pregnant women (0.88-0.91). ${ }^{36}$ The standard cutoff point of 16 was used to determine elevated distress. ${ }^{37}$ This cutoff point has been used as an indicator of clin- 
ically significant elevated depressive symptomatology in community samples ${ }^{38}$ as well as with pregnant women. ${ }^{36,39}$

Measures of past history of depression and treatment for depression were also included in the screening questionnaire. Past history was measured using items focusing on depression that were derived from the Diagnostic Interview Schedule (DIS-III-R). ${ }^{40}$ These items included questions assessing lifetime depression and recent depression (within the last 6 months) by asking participants if within the specified time frame, ". . . you had two weeks or more when nearly every day you felt sad, blue, or depressed or in which you lost all interest in things like work?" The sensitivity of these items as screeners for depression were found to range between 0.83 and 0.94. ${ }^{41}$ Finally, current treatment for depression was assessed with two items. Women were asked to indicate if they were currently receiving counseling, psychotherapy, or medication for depression or emotional problems (dichotomously coded, yes/no). A second item asked women to indicate the number of sessions they have had with a counselor or therapist for depression in the last 3 months.

\section{Data analysis plan}

Descriptive information on study participants was examined and is shown in Table 1 . We were also interested in descriptive information on depression-related items, such as rates of past history of depression and rates of current treatment for depression among those at risk (as measured by self-reports of depression in the past 6 months and by current elevated CES-D). Therefore, prevalence of this depression-related information was also examined for our sample.

The primary analyses for this study focused on demographic and health behavior variables associated with elevated depressive symptomatology, as measured by CES-D. Bivariate logistic regression was used to examine the factors associated with elevated depression. Women were divided into two groups based on their CES-D score, $\geq 16$ and $<16$, and this was used as the outcome variable in the analyses. Independent variables were selected based on previously studied demographic and health-related correlates of perinatal depression. The independent variables were maternal age, marital status, education, racial/ethnic status, employment status, parity, number of weeks gestation, lifetime history of depression, self-rated overall health, smoking during pregnancy, and alcohol use problems as measured by TWEAK. Independent variables were entered simultaneously in a single equation. This method allows for examination of the association of each independent variable to the outcome variable after controlling for all other variables in the equation. Thus, the influence of each variable on the outcome variable is calculated above and beyond every other variable in the equation. ${ }^{42}$ Overall model and individual variable statistics are presented along with odds ratios (ORs) for significant factors.

\section{RESULTS}

\section{Descriptions of depression}

Overall, $20.4 \% \quad(n=689)$ of pregnant women screened showed elevated depressive symptomatology as measured by a CES-D score of $\geq 16$. Of these women, $13.8 \%(n=91)$ reported that they currently were receiving any kind of formal treatment for depression (defined as any psychotherapy, medications, or counseling). The majority of women with elevated CES-D reported receiving no session with a counselor or therapist in the past 3 months $(85 \%)$, and $7 \%$ reported less than one session per month with a counselor or therapist in the past 3 months. Of those who reported depression in the past 6 months $(8.6 \%, n=297)$ (as measured by 2 weeks or more of feeling sad, blue, depressed or losing all interest in things such as work), $24.6 \%$ reported currently receiving any form of treatment for depression. Given the high risk of relapse among those with any prior history of depression, we were also interested in the rates of elevated depressive symptomatology among women with a past history. A total of $958(28 \%)$ women reported a lifetime history of major depression (as measured by 2 weeks or more of feeling sad, blue, depressed or losing all interest in things such as work). Of those, $42.6 \%(n=398)$ reported current elevated depressive symptomatology (based on CES-D cutoff $\geq 16$ ).

\section{Factors associated with elevated depressive symptomatology}

Bivariate logistic regression analysis was performed using elevated CES-D as the outcome variable, with the following independent variables: maternal age, marital status, race/ethnic- 
ity, education (i.e., number of years of school completed), maternal employment status, number of weeks gestation, parity, lifetime history of depression (yes/no), self-rated overall health, alcohol use problems as measured by TWEAK, and number of cigarettes smoked per day during pregnancy. The overall chi-square for the model was found to be significant (chi-square $=559(11)$, $p=0.000)$. Residuals and goodness-of-fit were checked in the final model (Hosmer and Leme show test chi-square $p$ value $=0.86$ ). There was no evidence of lack of fit in the final model.

Logistic regression statistics, including standardized coefficients, $p$ values, and ORs associated with each study variable, are presented in Table 2. Holding all other factors constant, women who reported a prior history of depression were 4.9 times more likely to have an elevated CES-D than women who reported no such history. Women who rated their overall health as poorer, who had greater alcohol use problems (as measured by TWEAK), and who smoked more cigarettes per day while pregnant were significantly more likely to have elevated CES-D. (OR = $1.5,1.2$, and 1.1, respectively). Women with lower educational attainment, those who were not working, and those unmarried or without a livein partner were also significantly more likely to have elevated depressive symptomatology (OR = $0.90,0.74$, and 0.57, respectively). Maternal age, parity, number of weeks gestation, and race/ethnicity were found to be unrelated to CES-D.

\section{DISCUSSION}

Our data show that a substantial number $(20 \%)$ of pregnant women screened antenatally in obstetrics settings reported significant depressive symptomatology. Most (86\%) were not receiving any treatment (defined as medication, psycho-therapy, or counseling) during this vulnerable time. Routine monitoring for depression does not occur in most obstetrics settings, including those used as the study sites. Thus, although not directly assessed, it is likely that these women were not being monitored by a healthcare professional for possible worsening of symptoms. Almost half of the women in our sample with a self-reported past history of major depressive disorder (MDD) (42.5\%) reported recurrence of mood symptoms during the pregnancy.

Although the impact of mood symptoms on the developing fetoplacental unit has not been fully elucidated, preliminary human and animal studies suggest that untreated psychiatric symptoms may impact the developing fetus and adversely affect neonatal outcome.7,43-46 Thus, antenatal screening in this population may identify women who may be at risk for such adverse pregnancy outcomes as prematurity and preeclampsia, enabling appropriate obstetric surveillance. As many women who develop postpartum depression have antecedent symptoms during pregnancy, screening for mood symptoms during pregnancy may also identify women at high risk for postpartum depression. ${ }^{47}$

Table 2. Standardized Regression Coefficients, Statistics, $p$ Values, and Odds Ratios for Variables Predicting Elevated Depressive Symptomatology a as in Pregnant Women Screened in Obstetrics Settings $(n=2991)^{\mathrm{b}}$ Based on Bivariate Logistic Regression

\begin{tabular}{lcccc}
\hline Variable & $B$ & Wald & p value & Odds ratio \\
\hline Maternal age & -0.02 & 2.6 & $\mathrm{NS}$ & - \\
Marital status & -0.56 & 15.6 & 0.00 & 0.57 \\
Minority & 0.10 & 0.69 & $\mathrm{NS}$ & - \\
Education & -0.10 & 4.0 & 0.04 & 0.90 \\
Employment status & -0.30 & 0.5 & 0.01 & - \\
No. of weeks gestation & 0.00 & 1.5 & $\mathrm{NS}$ & - \\
Parity & 0.06 & 241.5 & 0.00 & 4.9 \\
Lifetime depression (yes/no) & 1.6 & 40.2 & 0.00 & 1.5 \\
Self-rated health & 0.39 & 18.9 & 0.00 & 1.2 \\
TWEAK & 0.211 & 8.7 & 0.00 & 1.1 \\
Smoking while pregnant & 0.13 & &
\end{tabular}

\footnotetext{
${ }^{\mathrm{a} C e n t e r}$ for Epidemiological Studies-Depression Scale cutoff score $<16$ or $\geq 16$.

$b_{n}$ is smaller than total sample because of listwise deletion of missing variables included in the logistic regression analysis.

'Significance levels based on $p<0.05$.
} 
In fact, screening for depression in obstetrics settings appears to be feasible, as we were able to obtain surveys on 3472 pregnant women in 10 clinics over a 3-year period. The majority of women approached ( $90 \%$ ) agreed to complete the screening survey. Our study demonstrated that administration and scoring of screening tools can be done successfully by nonclinical staff (in this study, undergraduate research assistants).

The efficiency of screening in obstetrics may be improved by identification of risk factors for depressive symptomatology and depression risk. We found several factors to be strongly predictive of depressive symptoms during pregnancy. These include previous episodes of major depressive illness, poor self-rated health, and greater alcohol use and use of cigarettes while pregnant. Demographic factors, such as not living with a spouse/significant other, not working, and less education, were also significantly related to elevated symptoms of depression during pregnancy. Other demographic and socioeconomic factors as well as health behaviors, such as age, parity, stage of pregnancy, and race, were not correlated with pregnancy-related depression. As has been found in other studies of predictors of postnatal depression, self-reported prior history of depression was most strongly related to elevated depressive symptomotology during pregnancy. ${ }^{48}$ Thus, women with a past history of depression should be targeted for more intensive assessment during early pregnancy. Similarly, as our data suggest, it may be useful for physicians or other clinical staff to flag those not working, those unmarried, those with greater health complaints, and those who use alcohol and cigarettes as possible markers of elevated depression.

Such women represent a critical subpopulation who could benefit from more intensive assessment and intervention. More research is needed on optimal and appropriate treatment for women with antenatal minor or major depression. In the meantime, women, their families, and their physicians should be made aware of current knowledge on the safety and efficacy of pharmacological and psychotherapeutic treatments. For example, interpersonal psychotherapy has been found to be efficacious for the treatment of postnatal depression. ${ }^{49} \mathrm{~A}$ risk-benefit model of treatment decision making that considers a variety of factors related to the well-being of the mother and infant has been proposed..$^{23}$

Several limitations should be noted in inter- preting the results of this study. First, research assistants were used to collect screening data, which raises questions about the generalizability of implementation of large-scale screening efforts. Women were largely receptive to completing a brief screening survey while they waited for their prenatal care visits. However, future studies should examine the feasibility of implementation by clinical or clerical staff. Second, our study used measures of self-report for depression symptomatology and did not obtain diagnoses of MDD. Moreover, the study included only a single time for assessment of mood symptoms, collecting the self-report at variable times during the pregnancy (3-41 weeks) and not monitoring the course of the illness per se. Although distress and minor depression can be very debilitating and are associated with adverse pregnancy outcomes, additional work on the prevalence of MDD and its impact during pregnancy must be completed. Although the majority of those at risk reported not receiving any treatment, it is unclear if all of these women would necessarily benefit from treatment. We also do not have more specific information on any treatment or healthcare related to depression beyond the use of medications, psychotherapy, or counseling. Although these represent the treatment options for depression that have received the most study, there may be other types of interventions that women use that may be useful for their symptoms (e.g., religious advisement). Future studies may identify predictors of response to treatment along the continuum of depression. The impact of such treatment interventions on fetal and infant neurodevelopment must be further explored as well. Data obtained from this project highlight that depressive symptomatology is common in obstetrics settings. Research and clinical emphasis on appropriately targeted treatment will likely improve symptoms and overall functioning of these women and may help to minimize the adverse consequences of maternal mood symptoms on pregnancy outcomes.

\section{REFERENCES}

1. Kessler R, McGonagle $\mathrm{K}, \mathrm{Zhao} \mathrm{S}$, et al. Lifetime and 12 month prevalence of DSM-III-R psychiatric disorders in the United States. Arch Gen Psychiatry 1994; 51:8.

2. Spinelli MG. Antepartum and postpartum depression. J Gender-Specific Med 1998;1:33. 
3. Burke KC, Burke JD, Rae DS, Regier DA. Comparing age at onset of major depression and other psychiatric disorders by birth cohorts in five U.S. community populations. Arch Gen Psychiatry 1991;48:789.

4. Cooper PJ, Murray L. Course and recurrence of postnatal depression: Evidence for the specificity of the diagnostic concept. Br J Psychiatry 1995;152:799.

5. Kumar R, Robson KM. A prospective study of emotional disorders in childbearing women. Br J Psychiatry 1984;144:35.

6. O'Hara MW, Neunaber DJ, Zekoski EM. A prospective study of postpartum depression: Prevalence, course and predictive factors. J Abnorm Psychol 1984; 93:158.

7. Steer RA, Scholl TO, Hediger ML, Fischer RL. Self-reported depression and negative pregnancy outcomes. I Clin Epidemiol 1992;45:1093.

8. Kurki T, Hiilesmaa V, Raitasalo R, Mattila H, Ylikorkala O. Depression and anxiety in early pregnancy and risk for preeclampsia. Obstet Gynecol 2000;95:487.

9. McKee MD, Cunningham M, Jankowski KR, Zayas L. Health-related functional status in pregnancy: Relationship to depression and social support in a multiethnic population. Obstet Gynecol 2001;97:988.

10. Evans J, Heron J, Francomb H, Oke H, Golding J. Cohort study of depressed mood during pregnancy and after childbirth. Br Med J 2001;323:257.

11. Zuckerman B, Bauchner H, Parker S, et al. Maternal depressive symptoms during pregnancy, and newborn irritability. J Dev Behav Pediatr 1990;11:190.

12. Field T, Healy B, Goldstein S, et. al. Infants of depressed mothers show depressed behavior even with non-depressed adults. Child Dev 1988;59:1569.

13. Coghill SR, Caplan HL, Alexandra H, Robson K, Kumar R. Impact of maternal postnatal depression on cognitive development of young children. Br Med J 1986;292:1165.

14. Alpern L, Lyons-Ruth K. Preschool children at social risk: Chronicity and timing of maternal depressive symptoms and child behavior problems at school and at home. Dev Psychopathol 1993;5:371.

15. Leadbetter BJ, Bishop SJ. Predicators of behavior problems in preschool children of inner-city AfroAmerican and Puerto Rican adolescent mothers. Child Dev 1994;65:638.

16. Judd LL, Akiskal HS, Zellar PJ, et al. Psychosocial disability during the long-term course of unipolar major depressive disorder. Arch Gen Psychiatry 2000;57: 375.

17. Rapaport MH, Lewis L, Judd MD, et al. A descriptive analysis of minor depression. Am J Psychiatry 2002; 159:637.

18. Judd LL, Martin PP, Wells KB, Rapaport MH. Socioeconomic burden of subsyndromal depressive symptoms and major depression in a sample of the general population. Am J Psychiatry 1996;153:1411.

19. Weinberg MK, Tronick EZ, Beeghly M, Olson KL, Kernan H, Riley J. Subsyndromal depressive symptoms and major depression in postpartum women. Am J Orthopsychiatry 2001;71:87.
20. Kelly RH, Zatsick DF, Anders TF. The detection and treatment of psychiatric and substance use disorders among pregnant women cared for in obstetrics. Am J Psychiatry, 2001;158:213.

21. Marcus SM, Barry KL, Flynn HA, Blow FC. Improving detection, prevention and treatment of depression and substance abuse in childbearing women: Critical variables in pregnancy and pre-pregnancy planning. University of Michigan Clinical Ventures Grant through Faculty Group Practice Pilot Data, 1998.

22. Pignone MP, Gaynes BN, Rushton JL, et al. Screening for depression in adults: A summary of the evidence for the U.S. Preventive Services Task Force. Ann Intern Med 2002;136:765.

23. Wisner KL, Zarin DA, Holmboe ES, et al. Risk-benefit decision making for treatment of depression during pregnancy. Am J Psychiatry 2000;157:1933.

24. Altshuler LL, Hendrick V, Cohen LS. Course of mood and anxiety disorders during pregnancy and the postpartum period. J Clin Psychiatry 1998;59:9.

25. O'Hara MW. Social support, life events, and depression during pregnancy and the puerpium. Arch Gen Psychiatry 1986;43:569.

26. Pajulo M, Savonlahti E, Sourander A, Helenius H, Piha J. Antenatal depession, substance dependency and social support. J Affective Disord 2001;65:9.

27. Hanna E, Faden V, Dufour MC. The motivational correlates of drinking, smoking, and illicit drug use during pregnancy. J Substance Abuse 1994;6:155.

28. Zhu SH, Valbo A. Depression and smoking during pregnancy. Addict Behav 2002;27:649.

29. Bolton HL, Hughes PM, Turton P, Sedgwick P. Incidence and demographic correlates of depressive symptoms during pregnancy in an inner city London population. J Psychosom Obstet Gynaecol 1998;19:202.

30. Coyne JC, Pepper CM, Flynn H. Significance of prior episodes of depression in two patient populations. I Consult Clin Psychol 1999;67:76.

31. U.S. Census Bureau, 2002 Michigan Census Data.

32. Russell M. New assessment tools for risk drinking during pregnancy. Alcohol World 1994;18:55.

33. Bradley KA, Boyd-Wickizer J, Powell SH, Burman ML. Alcohol screening questionnaires in women: a critical review. JAMA 1998;280:166.

34. Fechner-Bates S, Coyne JC, Schwenk TL. The relationship of self-reported distress to depressive disorders and other psychopathology. I Consult Clin Psychol 1994;62:550.

35. Corcoran K, Fisher J. Measures for clinical practice: A sourcebook. New York: Free Press, 1987.

36. NICHD Early Child Care Research Network. Chronicity of maternal depressive symptoms, maternal sensitivity, and child functioning at 36 months. Dev Psychol 1999;35:1297.

37. Husaini BA, Neff JA, Harrington JB, Hughes MD, Stone RH. Depression in rural communities: Validating the CES-D scale. J Community Psychol 1980;8:20.

38. Myers JK, Weissman MM. Use of a self-report symptom scale to detect depression in a community sample. Am J Psychiatry 1980;137:1081. 
39. Beeghly M, Weinberg M, Olson K, Kernan H, Riley, J, Tronick E. Stability and change in level of maternal depressive symptomatology during the first postpartum year. J Affective Disord 2002;71:169.

40. Robins LN, Helzer JE, Croughan J, Ratcliff KS. National Institute of Mental Health Diagnostic Interview Schedule: Its history, characteristics and validity. Arch Gen Psychiatry 1981;38:381.

41. Rost K, Burnam M, Smith R. Development of screeners for depressive disorders and substance abuse disorder history. Med Care 1993;31:189.

42. Tabachnick BG, Fidell LS. Using multivariate statistics, 3rd ed. New York: Harper Collins, 1996.

43. Cohen LS, Rosenbaum JF, Heller VL. Panic attackassociated placental abruption: A case report. I Clin Psychiatry 1989;50:266.

44. Istvan J. Stress, anxiety, and birth outcome: A critical review of the evidence. Psychol Bull 1986;100:331.

45. Perkin MR, Bland JM, Peacock JL, et al. The effect of anxiety and depression during pregnancy on obstetric complications. Br J Obstet Gynaecol 1993;100:629.
46. Orr S, Miller C. Maternal depressive symptoms and the risk of poor pregnancy outcome: Review of the literature and preliminary findings. Epidemiol Rev 1995;17:165.

47. Watson JP, Elliot SA, Rugg AJ, Brough DI. Psychiatric disorder during pregnancy and the first postnatal year. Br J Psychiatry 1984;144:453.

48. Beck CT. Predictors of postpartum depression. Nurs Res 2001;50:275.

49. $\mathrm{O}^{\prime}$ Hara MW, Stuart S, Gorman LL, Wenzel A. Efficacy of interpersonal psychotherapy for postpartum depression. Arch Gen Psychiatry 2000;57:1039.

Address reprint requests to: Sheila M. Marcus, M.D. University of Michigan 900 Wall Street Ann Arbor, MI 48109-0722

E-mail: smmarcus@umich.edu 


\section{This article has been cited by:}

1. A. Oppo, M. Mauri, D. Ramacciotti, V. Camilleri, S. Banti, C. Borri, C. Rambelli, M. S. Montagnani, S. Cortopassi, A. Bettini, S. Ricciardulli, S. Montaresi, P. Rucci, C. T. Beck, G. B. Cassano. 2009. Risk factors for postpartum depression: the role of the Postpartum Depression Predictors Inventory-Revised (PDPI-R). Archives of Women's Mental Health 12:4, 239-249. [CrossRef]

2. Ma. Asunción Lara, Huynh-Nhu Le, Gabriela Letechipia, Laila Hochhausen. 2009. Prenatal Depression in Latinas in the U.S. and Mexico. Maternal and Child Health Journal 13:4, 567-576. [CrossRef]

3. Jane M. Onoye, Deborah Goebert, Leslie Morland, Courtenay Matsu, Tricia Wright. 2009. PTSD and postpartum mental health in a sample of Caucasian, Asian, and Pacific Islander women. Arcbives of Women's Mental Health . [CrossRef]

4. Laura Miller, Michele Shade, Vamsi Vasireddy. 2009. Beyond screening: assessment of perinatal depression in a perinatal care setting. Archives of Women's Mental Health . [CrossRef]

5. Barbara Figueiredo, Raquel Costa. 2009. Mother's stress, mood and emotional involvement with the infant: 3 months before and 3 months after childbirth. Archives of Women's Mental Health 12:3, 143-153. [CrossRef]

6. Margaret S. Chisolm, Michelle Tuten, Eric C. Strain, Hendrée E. Jones. 2009. Screening for Mood Disorder in Pregnant Substance-dependent Patients. Addictive Disorders \& Their Treatment 8:2, 88-98. [CrossRef]

7. G. Spies, D. J. Stein, A. Roos, S. C. Faure, J. Mostert, S. Seedat, B. Vythilingum. 2009. Validity of the Kessler 10 (K-10) in detecting DSM-IV defined mood and anxiety disorders among pregnant women. Archives of Women's Mental Health 12:2, 69-74. [CrossRef]

8. Janice H. Goodman. 2009. Women's Attitudes, Preferences, and Perceived Barriers to Treatment for Perinatal Depression. Birth 36:1, 60-69. [CrossRef]

9. Marlene P. Freeman, Paul E. Nolan, Melinda F. Davis, Marietta Anthony, Karen Fried, Martha Fankhauser, Raymond L. Woosley, Francisco Moreno. 2009. Pharmacokinetics of Sertraline Across Pregnancy and Postpartum. Journal of Clinical Psychopharmacology 28:6, 646-653. [CrossRef]

10. Doris McGartland Rubio, Kevin L. Kraemer, Max H. Farrell, Nancy L. Day. 2008. Factors Associated With Alcohol Use, Depression, and Their Co-occurrence During Pregnancy. Alcoholism: Clinical and Experimental Research 32:9, 1543-1551. [CrossRef]

11. Katherine J Gold, Sheila M Marcus. 2008. Effect of maternal mental illness on pregnancy outcomes. Expert Review of Obstetrics \& Gynecology 3:3, 391-401. [CrossRef]

12. Erin Salkeld, Lorraine E. Ferris, David N. Juurlink. 2008. The Risk of Postpartum Hemorrhage With Selective Serotonin Reuptake Inhibitors and Other Antidepressants. Journal of Clinical Psychopharmacology 28:2, 230-234. [CrossRef]

13. Sherryl H. Goodman, Erin C. Tully. 2008. Recurrence of depression during pregnancy: psychosocial and personal functioning correlates. Depression and Anxiety n/a-n/a. [CrossRef]

14. Melissa Page, Mari S. Wilhelm. 2007. Postpartum Daily Stress, Relationship Quality, and Depressive Symptoms. Contemporary Family Therapy 29:4, 237-251. [CrossRef]

15. B. Figueiredo, A. Pacheco, R. Costa. 2007. Depression during pregnancy and the postpartum period in adolescent and adult Portuguese mothers. Archives of Women's Mental Health 10:3, 103-109. [CrossRef]

16. ELYSIA POGGI DAVIS, LAURA M. GLYNN, CHRISTINE DUNKEL SCHETTER, CALVIN HOBEL, ALEKSANDRA CHICZ-DEMET, CURT A. SANDMAN. 2007. Prenatal Exposure to Maternal Depression and Cortisol Influences Infant Temperament. Journal of the American Academy of Child \& Adolescent Psychiatry 46:6, 737-746. [CrossRef]

17. R. Hart, C. A. McMahon. 2006. Mood state and psychological adjustment to pregnancy. Archives of Women's Mental Health 9:6, 329-337. [CrossRef]

18. Heather A. Flynn, Heather A. O'mahen, Lynn Massey, Sheila Marcus . 2006. The Impact of a Brief Obstetrics Clinic-Based Intervention on Treatment Use for Perinatal DepressionThe Impact of a Brief Obstetrics Clinic-Based 
Intervention on Treatment Use for Perinatal Depression. Journal of Women's Health 15:10, 1195-1204. [Abstract] [PDF] [PDF Plus]

19. Jennifer R. Pippins, Phyllis Brawarsky, Rebecca A. Jackson, Elena Fuentes-Afflick, Jennifer S. Haas . 2006. Association of Breastfeeding with Maternal Depressive SymptomsAssociation of Breastfeeding with Maternal Depressive Symptoms. Journal of Women's Health 15:6, 754-762. [Abstract] [PDF] [PDF Plus]

20. Pierre Buekens, Xu Xiong, Emily Harville. 2006. Hurricanes and Pregnancy. Birth 33:2, 91-93. [CrossRef]

21. Victoria Mosack, Elsie Shore. 2006. Screening for Depression Among Pregnant and Postpartum Women. Journal of Community Health Nursing 23:1, 37-47. [CrossRef]

22. Sara L. Sohr-Preston, Laura V. Scaramella. 2006. Implications of Timing of Maternal Depressive Symptoms for Early Cognitive and Language Development. Clinical Child and Family Psychology Review 9:1, 65-83. [CrossRef]

23. Victoria H. Coleman, Maria A. Morgan, Stanley Zinberg, Jay Schulkin. 2006. Clinical Approach to Mental Health Issues Among Obstetrician???Gynecologists: A Review. Obstetrical \& Gynecological Survey 61:1, 51-58. [CrossRef]

24. Thomas R. Einarson, Adrienne Einarson. 2006. Newer antidepressants in pregnancy and rates of major malformations: a meta-analysis of prospective comparative studies. Pharmacoepidemiology and Drug Safety 14:12, 823-827. [CrossRef]

25. L. Bonari, G. Koren, T. R. Einarson, J. D. Jasper, A. Taddio, A. Einarson. 2005. Use of antidepressants by pregnant women: Evaluation of perception of risk, efficacy of evidence based counseling and determinants of decision making. Archives of Women's Mental Health 8:4, 214-220. [CrossRef]

26. Heather A Bennett, Adrienne Einarson, Anna Taddio, Gideon Koren, Thomas R Einarson. 2004. Depression during Pregnancy. Clinical Drug Investigation 24:3, 157-179. [CrossRef]

27. Heather A. Bennett, Thomas R. Einarson . 2004. Depressive Symptoms among Women Screened in Obstetrics SettingsDepressive Symptoms among Women Screened in Obstetrics Settings. Journal of Women's Health 13:1, 119-119. [Citation] [PDF] [PDF Plus]

28. Heather A. Flynn, Sheila M. Marcus . 2004. ResponseResponse. Journal of Women's Health 13:1, 120-120. [Citation] [PDF] [PDF Plus] 